\section{P341 TRENDS IN CONDOM USE AMONG A NATIONALLY REPRESENTATIVE SAMPLE OF WOMEN AND MEN WITH OPPOSITE-SEX PARTNERS IN THE U.S}

${ }^{1}$ Patricia Dittus*, ${ }^{2}$ Casey Copen, ${ }^{3}$ Jami Leichliter, ${ }^{4}$ Sagar Kumar, ${ }^{5}$ Sevgi Aral. ${ }^{1} C D C$, Division of STD Prevention, Atlanta, USA; ${ }^{2}$ Centers for Disease Control and Prevention, Division of STD Prevention, Atlanta, USA; ${ }^{3} \mathrm{CDC}$, Atlanta, USA; ${ }^{4}$ Centers for Disease Control and Prevention, Atlanta, USA; ${ }^{5} \mathrm{CDC}$, Atlanta, USA

\subsection{6/sextrans-2019-sti.449}

Background As STIs continue to increase in the United States, one possible explanation is that declines in condom use have contributed to these increases. To date, condom use trends from nationally representative data on individuals with opposite-sex partners have not been examined.

Methods We used data from the National Survey of Family Growth (2002, 2006-10, 2011-15) to examine trends in condom use at last sex among unmarried, non-cohabiting women and men aged 15-44 with past-year opposite-sex partners, by race/ethnicity (Hispanic, non-Hispanic white, non-Hispanic black), age (15-24, 25-29, 30-44), any past-year non-monogamy (two or more partners or perceived partner non-monogamy), and past-year STI testing. Year of survey was included as a categorical variable. Chi-square tests and adjusted prevalence ratios were used to test differences in the prevalence of condom use in 2002, 2006-2010 and 2011-2015.

Results Overall, condom use prevalence remained stable among women (2002, 35.5\%; 2006-10, 39.1\%, 2011-15, 37.4\%) and among men $(2002,49.4 \% ; 2006-10,53.3 \%, 2011-15$, $53.3 \%$ ), with no differences in temporal trends by race/ethnicity or age in adjusted models. Any reported non-monogamy was also not associated with changes in condom use over time for any group. There was a significant decline in condom use among women aged 30-44 who reported STI testing, from 2006-10 to 2011-15 (36.3\%, 95\%CI: 29.4-43.1; 25.0\%, 95\%CI: 20.8-29.2, respectively), and among non-Hispanic black men who reported STI testing, from 2002 to 2006-10 (77.9\%, 95\%CI: 68.9-86.8; 61.8\%, 95\%CI: 54.669.0 , respectively).

Conclusion Overall and for most subgroups, condom use has remained stable over time, suggesting it is not contributing to increases in STI. Models adjusting for demographics suggest these results are not due to demographic shifts. However, certain sub-groups may be using STI testing as a protective strategy when not using condoms. Examination of other explanatory factors is needed.

Disclosure No significant relationships.

\section{P343 PRIMARY OUTCOMES FROM IMPLEMENTING A BEHAVIORAL COUNSELING INTERVENTION PROGRAM IN FOUR FEDERALLY QUALIFIED HEALTH CENTERS}

Kathryn Brookmeyer*, Casey Copen, Dan Lentine, Matthew Hogben. Centers for Disease Control and Prevention, Division of STD Prevention, Atlanta, USA

\subsection{6/sextrans-2019-sti.450}

Background The U.S. Preventive Services Task Force (USPSTF) recommends behavioral counseling for youth at high-risk for STDs, but little work has explored translation of these guidelines into practice. Here, we evaluated a large-scale implementation of behavioral counseling in federally qualified health centers (FQHCs).
Methods Implementation occurred between June 2017 and May 2018 in four FQHCs in Northeastern US. Many patients were below the poverty level $(27-65 \%)$ or uninsured (13$47 \%)$. Training content comprised motivational interviewing skills and techniques for talking to youth about sex and sexual histories, delivered to pilot providers via 15 hours of online and in-person training. We measured the proportion of patients who received (a) a sexual history, (b) behavioral counseling, (c) HPV vaccine and (d) chlamydia screening. We tracked changes in work-flow and implementation and allowed for tailoring of sexual history taking per the needs of FQHCs. Results 39,631 eligible patients (13-24 years old, 71.0\% Hispanic, $68.3 \%$ white, $24.9 \%$ black) were seen during the implementation period, of whom 9,675 (24.4\%) saw a pilot provider. Similar proportions in each group completed a sexual history $(70.6 \%$ vs. $71.4 \%, \mathrm{p}=0.1787)$. However, higher proportions of patients exposed to the pilot providers received behavioral counseling $(67.5 \%$ vs. $43.5 \%, \mathrm{p}<0.0001)$, HPV vaccine $(71.7 \%$ vs. $51.2 \%, \mathrm{p}<0.0001)$ and chlamydia screening $(38.4 \%$ vs.32.1\%, $\mathrm{p}<0.0001)$. Of youth who were seen by a pilot provider and given a sexual history, $84.2 \%$ received behavioral counseling. Of counseled patients, $83.6 \%$ received HPV vaccine and $85.2 \%$ were screened for chlamydia. Work flows were individualized to each health center and became increasingly efficient over time.

Conclusion Primary outcomes from this translation study support the conclusion that an intensive, but short, training regimen on behavioral counseling, coupled with a flexible strategy for assessing sexual histories, results in higher rates of behavioral counseling and provision of prevention services as compared to those who did not receive training.

Disclosure No significant relationships.

\section{P344 TRANSMUTATION IN HIGH-RISK SEXUAL BEHAVIOR OF MEN IN INDIA: AN ASSESSMENT OF MAGNITUDE AND PREDICTORS}

Santosh Sharma*. International Institute for Population Sciences, Population Studies, Mumbai, India

\subsection{6/sextrans-2019-sti.451}

Background Modern Indian society has witnessed rapid sociocultural transformation where loosening of cultural values is observed at all levels. In the era of transition, traditional norms and values are at change where young male individuals are found to be associated with high-risk multi-partner sexual behaviour. This study intends to determine the changes in magnitude and predictors of such high-risk sexual behaviour among men in India.

Methods The sample of 74,369 and 112,122 men aged 15-54 from two rounds of the National Family Health Survey (NFHS) conducted during 2005-2006 (NFHS-3) and 20152016 (NFHS-4) has been used. The economic inequalities in the prevalence of high-risk sexual behaviour have been analysed using poor-rich ratio, and concentration index (CI) in addition to adjusted effects of major correlates through multiple logistic-regressions.

Results The burden of high-risk sexual behaviours over the last decade remains disproportionately higher among younger, unmarried, urban men and mainly from better economically households. Despite tremendous efforts of the governments in condom promotion as part of HIV/AIDS prevention 